\title{
Experience of Using and Application Prospects \\ of Rolling-Extruding Process \\ for Obtaining Semi-Finished Products
}

from Aluminum Alloys

\author{
Sergey B. Sidelnikov*, Nikolai N. Dovzhenko, \\ Igor L. Konstantinov, Roman I. Galiev, \\ Andrey L. Kiselev and Anton P. Samchuk \\ Siberian Federal University \\ 79 Svobodny, Krasnoyarsk, 660041, Russia
}

Received 14.11.2014, received in revised form 16.01.2015, accepted 05.02.2015

Presented the experience of the application method of combined rolling-extruding of metals for obtaining semi-finished products from deformed and secondary aluminum alloys on combined treatment installations. Research the structure and properties, and the possibility of obtaining hot-extruded semi-finished products from recycled aluminum alloy AV93.

Keywords: aluminum alloys, combined rolling-extruding, electromagnetic crystallizer, mechanical properties.

\section{Опыт использования и перспективы применения процесса прокатки-прессования \\ для получения полуфабрикатов \\ из алюминиевых сплавов}

С.Б. Сидельников, Н.Н. Довженко, И.Л. Константинов, Р.И. Галиев, А.Л. Киселев, А.П. Самчук Сибирский федеральныий университет Россия, 660049, Красноярск, пр. Свободный, 79

Рассмотрен опыт применения метода совмещенной прокатки-прессования металлов для получения полуфабрикатов из деформируемых и вторичных алюминиевых сплавов на

(c) Siberian Federal University. All rights reserved

* Corresponding author E-mail address: sbs270359@yandex.ru 
установках совмещенной обработки. Изучены структура и свойства и показана возможность получения горячепрессованных полуфабрикатов из вторичного алюминиевого сплава АВ93.

Ключевые слова: алюминиевыесплавы, совмещенная прокатка-прессование, электромагнитный кристаллизатор, механические свойства.

\section{Introduction}

Traditional technology of obtaining long products using operations of rolling and extruding production is quite complicated and usually involves a large number of intermediate processing steps that increase the cost of metal production and reduce yield ratio. Recently acquired special relevance works aimed at creating technologies for products in which different types of metal (casting, heat treatment, rolling, extrusion, etc.) are combined in one cycle. This principle of combining the processes used in the high performance casting-rolling aggregates used for machining steel, aluminum and copper alloys. However, these units are different complex structure, occupy a large area, power consumption, focused on high-volume production and is not suitable for all alloys, making them ineffective in a fast transition from one profile to another. Moreover, they are not profitable for small production volumes.

Recently abroad to obtain profiles of a small section from aluminum and copper alloys are created mini-productions based on the technology of the new generation with the use of continuously extrusion (Conform, Extrolling, Linex) and continuous casting, rolling and pressing (Castex, Caster).

Equipment designed for such production is made up of individual modules is therefore characterized by high mobility, flexibility, transition from one size to another and relatively high performance. For the domestic industry the creation of such technologies will reduce the energy intensity of production and ensure the competitiveness of the obtained products. Therefore, the development of new technologies based on the use of combined, complex and continuous methods, modular equipment and mini-productions for their implementation, is one of the most important areas of development metal processing.

From the viewpoint of achieving high degrees of deformation for one operation, it is important to study the structure and, therefore, achieve high mechanical properties the most interesting is rollingextruding. This first treatment method called Extrolling been proposed and patented by B. Avitsur in 1976 and was a combination of rolling and pressing in a deformation zone according to the scheme shown in Fig. 1.

To carry out this process, the initial billet 6 continuously set in caliber 8 , pressed out by in it, which is fully consistent with the rolling step, and due to the excess of the active forces of friction is extruded into the sizing matrix aperture 3 , installed output from caliber. The method implemented for the extrusion of various metals and their alloys in the cold state and at high temperatures. Compared with traditional pressing reduces the cost of power is to overcome the friction of reactive action, as well as more effective cavity is filled with the caliber of the metal billet. Implementation of the process eliminates the disadvantages of such pressing as the limited length of the resulting product, and for rolling becomes possible to increase the single compression and raise them to the values obtained by extrusion. However, in this arrangement the deforming unit (see Fig. 1) may slip the metal relative to rolls and infringement of the stable process of metal deformation. The authors proposed patented technical solutions which allow increasing the feasibility of the process by using a closed caliber having a certain shape and aspect ratio, overlapped output by the matrix, spaced apart at a distance 


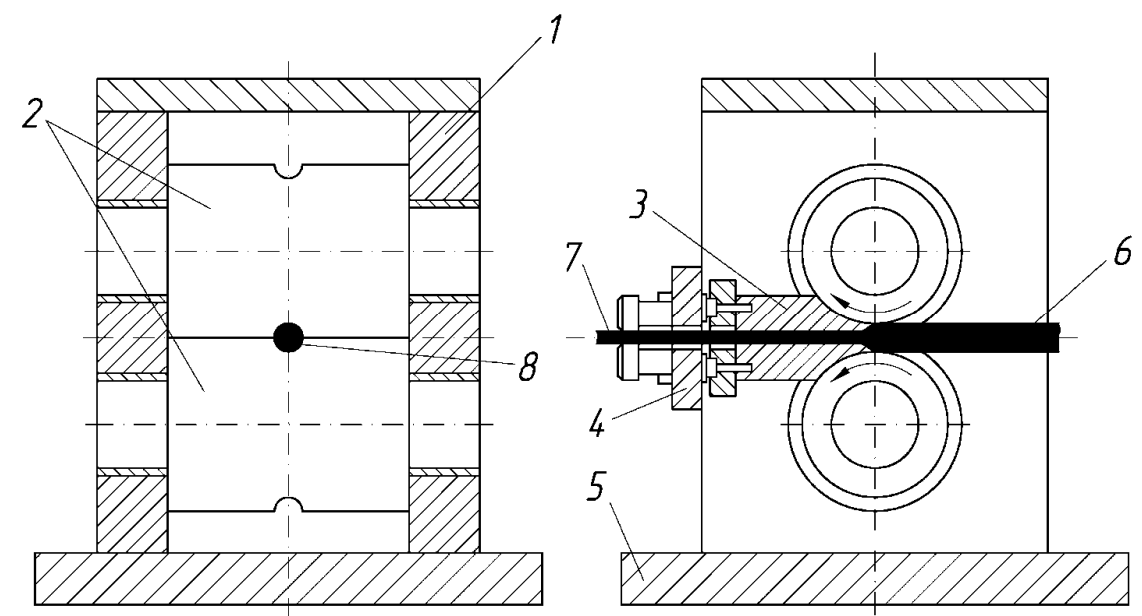

Fig. 1. Scheme of process Extrolling: 1 - frame; 2 - rolls; 3 - matrix; 4 - matrix holder; 5 - plate; 6 - billet; 7 - product; 8 - caliber with metal

from the common axis of rolls. This method, unlike the method Extrolling named CRE (combined rolling-extruding) [1].

It can be assumed that a large degree of deformation in conjunction with the favorable scheme for the manifestation plasticity stress status - comprehensively no uniform compression could make processable high-alloy pressure treatment, and not ductile hard-deformable aluminum alloys, including secondary alloys of aluminum. Therefore the aim of the work was to investigate the possibility of obtaining semi-finished deformed products by the CRE from the alloyed alloy AMg6 and secondary alloy AV93.

\section{Methodology of experiments}

After experimental researches carried out on pilot installation of department «Metal forming» Siberian federal university CRE-200, at «Verhnyaya-Salda metallurgical production association» JSC was installed and put into production installation of combined rolling-extrusion CRE-260 [1,2]. This setting is used to produce production from low-alloyed aluminum alloys. For working off industrial technology for obtaining bars of aluminum alloys, including hard-deformable and low-plasticity, based on the company "TK SEGAL" Ltd. was mounted installation CRE-400 [3]. The main unit of installment was rolling mill DUO 400 (Fig. 2) consisting of two closed-type machine beds, two rolls with a diameter of $400 \mathrm{~mm}$, gear, gear cage and motor capacity of $75 \mathrm{~kW}$. The rolls are made watercooled, consisting of a shaft and fixed on them with bandages key connection with streams (one in the form of a projection, the second a trough), which form a closed gauge. Clamp matrix unit to the rolls carried out by means hydraulic cylinders with a working pressure liquid of $35 \mathrm{MPa}$, providing clamping force of at least $400 \mathrm{kN}$. Thus, for feeding and discharging the coolant provided by a special device into the shaft and are made in the shroud cavity.

At present on the installation CRE-400 were modernized the drive (Fig. 3) and used gear-motor BONFIGLIOLI with output speed $4.8 \mathrm{rpm}$, reduction ratio 304, the nominal moment transmitted by the low-speed shaft of $35,000 \mathrm{Nm}$ and a electric motor power of $18.5 \mathrm{~kW}$. The further development 


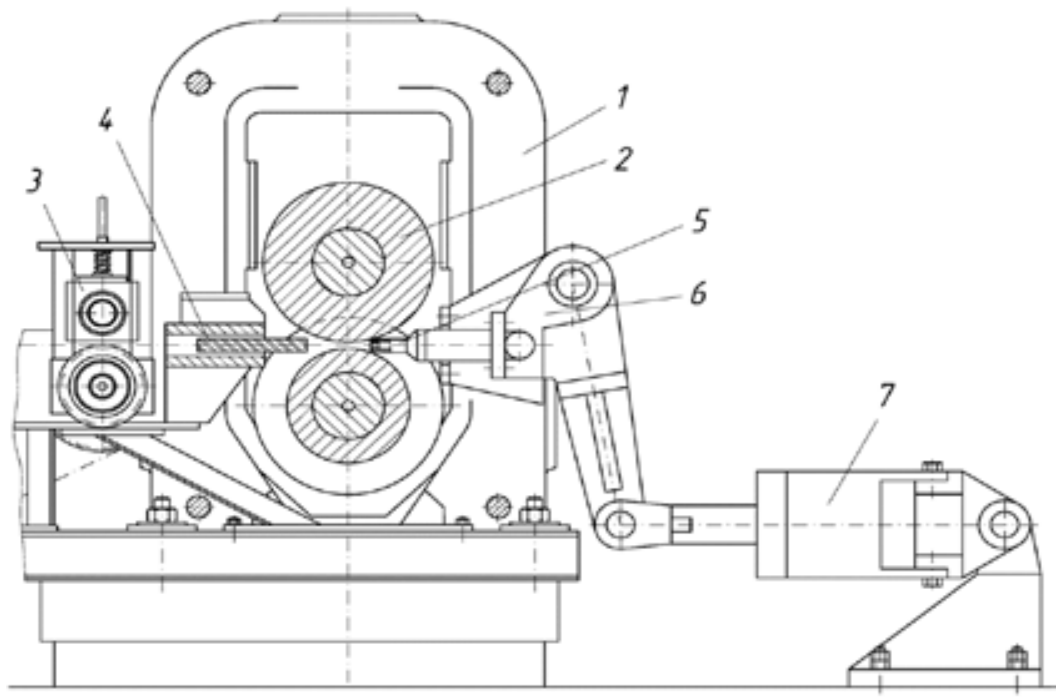

Fig. 2. Installment CRE-400: 1 - frame; 2 - rolls; 3 - correctly-setting device; 4 - billet; 5 - matrix; 6 - clamp; 7 - hydraulic cylinder

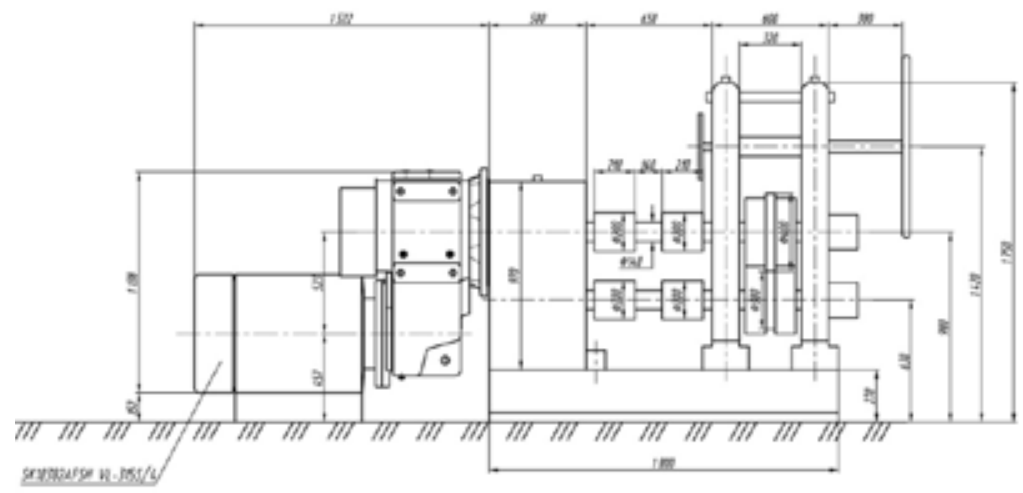

Fig. 3. Scheme of installment CRE-400 after modernization of drive

constructions of this equipment is to provide installations for the combined casting and rollingextrusion.

In the work carried out research on aluminum alloys AD1, AMg6 and AV93. Low-alloyed alloy AD1 used for the development of the technology of the rolling-extrusion process, mainly for the detection and calibration matrix assembly clamping force to the rolls. The chemical compositions of alloys AD1 and AMg6 according Standard 4784-97, and the alloy composition of AV93 shown in Table 1.

After rolling-extruding carried out mechanical tensile tests of semi-finished products by Standard 10446-80 on a universal electromechanical tensile testing machine LFM-400. When tested on one experimental point was taken five samples. Some bars were drawn with using drawing machine VSG$1 / 550 \mathrm{~A}$ followed by testing the mechanical properties of the wire after each pass of drawing. 
Table 1. Chemical composition of secondary aluminum alloy AV93

\begin{tabular}{|c|c|c|c|c|c|c|c|c|}
\hline \multirow{3}{*}{ Mark } & \multicolumn{8}{|c|}{ mass fraction, $\%$} \\
\hline & \multirow{2}{*}{$\begin{array}{c}\text { sum } \mathrm{Al} \text { and } \mathrm{Mg} \text {, } \\
\text { not less }\end{array}$} & \multirow{2}{*}{$\begin{array}{l}\text { including } \mathrm{Mg} \text {, } \\
\text { no more }\end{array}$} & \multicolumn{6}{|c|}{ Impurities, no more $\%$} \\
\hline & & & $\mathrm{Cu}$ & $\mathrm{Zn}$ & $\mathrm{Si}$ & $\mathrm{Sn}$ & As & all \\
\hline AV93 & 93 & 3,0 & 3,0 & 0,7 & 1,0 & 0,1 & 0,1 & 7,0 \\
\hline
\end{tabular}

Table 2. Parameters of rolling extruding for alloys AD1 and AMg6 on installment CRE-400

\begin{tabular}{|c|c|c|c|c|c|}
\hline Mark of alloy & $\begin{array}{c}\text { Roll } \\
\text { temperature, } \\
{ }^{\circ} \mathrm{C}\end{array}$ & $\begin{array}{c}\text { Matrix } \\
\text { temperature, } \\
{ }^{\circ} \mathrm{C}\end{array}$ & $\begin{array}{c}\text { Billet } \\
\text { temperature, } \\
{ }^{\circ} \mathrm{C}\end{array}$ & $\begin{array}{c}\text { The frequency } \\
\text { of rolls rotation, } \\
\mathrm{rpm}\end{array}$ & $\begin{array}{c}\text { The exhaust } \\
\text { velocity of rod, } \\
\mathrm{m} / \mathrm{min}\end{array}$ \\
\hline AD1 & $190-200$ & $170-300$ & $425-585$ & $2-2,25$ & $15-16$ \\
AMg6 & $350-380$ & $200-260$ & $430-480$ & 2,25 & $15-17$ \\
\hline
\end{tabular}

\section{Experimental part}

Development of the technology rolling-extrusion was carried out on aluminum AD1 mark. At startup installation determines the optimum clamping force of matrix node to the rolls. This parameter is important for installment operation as with little effort metal is squeezed into the gap between the rolls and the matrix, and not to the channel of matrix. Excessive contact pressure leads to the interaction surfaces of the rolls and matrix assembly and abrasion. For this purpose using hydraulic cylinder pressed the matrix node at various pressing force fixed metal thickness in the gap between the matrix and the rolls, the temperature of the heating rolls, matrix and billets. Optimum clamping force at which the metal does not penetrate into the gap between the rolls and the matrix was $260 \mathrm{kN}$. Next is the process of deformation of the metal from billets of square cross section $30 \times 30 \mathrm{~mm}$ and obtain experimental batches of rods diameter of $9-12 \mathrm{~mm}$ which are wound into coils weighing up to 75 $\mathrm{kg}$. Part of the billets were further drawing. After working regimes on the alloy AD1 spent extrusion AMg6 alloy (Table 2).

Hot-extruded coves billets from alloy AD1 was drawn to obtain wires of $3 \mathrm{~mm}$ diameter. After each drawing conducted tests of mechanical properties in tension with the definition of the ultimate tensile strength $\sigma_{s}$ and elongation $\delta$. The results of mechanical properties are shown in Table 3. It should be noted that the process of obtaining the wire diameter of $3 \mathrm{~mm}$ could be carried out without annealing and without breaks. Taking into account that lengthy billet was obtained by deformation of discrete billets, which characterizes a good quality welding of billets in the deformation zone during rolling-extrusion.

Getting the rods of alloy AMg6 performed on the same technology. The best results for the properties and surface quality rods were achieved by heating billets to a temperature of $430{ }^{\circ} \mathrm{C}$ with heating rolls $350^{\circ} \mathrm{C}$. Ultimate tensile strength of hot-extruded rods was $320 \mathrm{MPa}$, and elongation $\delta=12 \%$, ie almost at the level of properties imposed on these products by Standard 21488-97.

The next phase of research carried out on the billets of secondary alloy AV93. One of the main applications of secondary alloys type AV is the production of materials for the deoxidation of steel. Usually they are made in the form of ingots small mass and granules. Ingots have a mass of less than 
Table 3. Mechanical properties of wire from alloy АД1 by drawing steps

\begin{tabular}{|c|c|c|c|}
\hline № of pass & Sample diameter, $\mathrm{mm}$ & Ultimate tensile strength $\sigma_{\mathrm{B}}, \mathrm{MPa}$ & Elongation $\delta, \%$ \\
\hline 1 & 9,00 & 80 & 25,0 \\
2 & 8,50 & 115 & 7,0 \\
3 & 6,80 & 125 & 3,5 \\
4 & 5,88 & 135 & 4,0 \\
5 & 5,20 & 140 & 3,0 \\
6 & 4,55 & 145 & 3,0 \\
7 & 3,95 & 150 & 3,0 \\
8 & 3,45 & 155 & 3,0 \\
9 & 3,00 & 160 & 3,0 \\
\hline
\end{tabular}

$20 \mathrm{~kg}$ with no constrictions and pinched, and possibly the use of small ingots weighing up to $4 \mathrm{~kg}$. Granules are lentil shape (from spherical to ellipsoidal). Weight of separate granules should be from 0.5 to $15 \mathrm{~g}$, and its composition must not contain mechanical impurities. This type of semi-finished products has a number of disadvantages: non-uniformity of the chemical composition of the volume due to the dendrite liquation, cutting, usually carried out by cleaving ingots, makes it difficult to obtain accurate batches, shape deoxidizer in the form of pieces of different mass makes it impossible to supply a deoxidizer into the melt at a certain speed, which is important for effective passing the steel deoxidation process, etc.

Deoxidation sometimes use an aluminum rod, which is produced in Russia according to Standard 13843-78. This kind of deoxidizer is much more effective as it allows entering rod into the melt at a certain speed, which leads to uniformity of properties and the quality of the resulting steel. However, the main disadvantage of using such deoxidizer is a high cost.

The use of extruded semi-finished products from cheap secondary alloys as de-oxidants increases the efficiency of deoxidation of steel with little rise in price of products. However, the production of extruded semi-finished products of secondary aluminum alloys constrained by low technological ductility of these alloys. In domestic practice there is a positive experience deformation of similar alloys. Thus, in work [4] described the production of extruded semi-finished products from granules of secondary aluminum alloys. It was noted that the structure of extruded profiles from granules of secondary alloys remained severely comminuted and unrecrystallized as in hotpressed state and after heat treatment, indicating that its stability. An analysis of the mechanical properties showed that the main indicators of the mechanical properties $\left(\sigma_{B}, \delta\right)$ profiles obtained from granules of casting of secondary aluminum alloys, in heat-treated condition did not yield profiles of the primary deformable alloys. Stated allowed to assume the possibility of obtaining extruded bars of these alloys by CRE using the billet obtained with a high crystallization rate, such as an electromagnetic casting mold. This is confirmed by Technical solutions [5], in which the application for casting in electromagnetic crystallizer (EMC) and subsequent processing by CRE, by high intensity shear deformation allows you to prepare structures not only deformed in a alloys and casting and make it suitable for producing semi-finished products with high degree of deformation. 
Table 4. The mechanical properties of hot-pressed rods of alloy AV93 obtained by method CRE

\begin{tabular}{|c|c|c|c|c|}
\hline \multirow{2}{*}{ Properties } & \multicolumn{3}{|c|}{ Billet heat temperature, ${ }^{\circ} \mathrm{C}$} \\
\cline { 2 - 5 } & \multicolumn{2}{|c|}{480} & \multicolumn{2}{c|}{525} \\
\cline { 2 - 5 } & \multicolumn{2}{|c|}{ Rod diameter, $\mathrm{mm}$} & 7 & 9 \\
\cline { 2 - 5 } & 7 & 9 & 355 & 315 \\
\hline$\sigma_{\mathrm{B}}(\mathrm{MPa})$ & 335 & 280 & 4 & 2,7 \\
\hline$\delta(\%)$ & 5 & 6 & & \multicolumn{2}{c|}{ Rod diameter, mm } \\
\hline
\end{tabular}

The process of forming an ingot in EMC proceeds as follows. The molten metal in the pulsating electromagnetic field of inducer experiences a force effect resulting from the interaction of the eddy currents induced in the metal, with the magnetic field of inductor. Volumetric forces acting in the metal in the direction of propagation of electromagnetic energy. Strong interaction between the currents in the metal and the field inductor leads to mutual repulsion of the metal and the inductor. As a result, the molten metal is under hydrostatic pressure, is deformed (compressed) in the radial direction. At compression the metal cross-section takes the form of inductor with the geometric dimensions defined by the magnetic field. The foregoing provides a uniform distribution of alloying elements and impurities by volume of the melt and, hence, the volume formed at the crystallization preform.

The work for the combined rolling- extrusion of secondary alloy AV93 used billet obtained by casting in EMC. CRE process was carried out at two temperatures, heating billets 480 and $525^{\circ} \mathrm{C}$. Mechanical properties of hot-pressed semi-finished products are presented in Table 4.

Performance analysis shown in table 4, showed that the strength of rods $9 \mathrm{~mm}$ lower than the diameter of rods 7 , which can be explained by a lower degree of deformation. It was also found that increasing the temperature of heating billets from 480 to $525^{\circ} \mathrm{C}$ leads to a decrease in ductility of the metal.

Metallographic examination revealed that the structure of rod of $7 \mathrm{~mm}$ diameter grains strongly pulled in the direction of deformation, as compared with $9 \mathrm{~mm}$ diameter rod, which is associated with a high degree of deformation (Fig. 4).

Structure of samples in longitudinal section represents grains elongated in the direction of deformation. At the grain boundaries are the eutectic phase of origin and include various insoluble elements. Application of different temperatures and deformation speeds significant influence on the properties of no effect. The microhardness is $89-97 \mathrm{kgf} / \mathrm{mm}^{2}$. Preparation of semi-finished products from aluminum mark AV93 by a combined rolling-extruding, so that helps to ensure a sufficiently small structure that provides the necessary mechanical properties of the finished product.

Currently, regulations (standards, processing instructions, and so on) do not regulate the mechanical properties of secondary aluminum alloys, but the analysis of the structure and mechanical properties of the metal above, allows us to recommend them for deoxidizing steel with wire rod instead of primary aluminum. Obtained with the CRE finished secondary alloys can be supplied in coil and serve in the steel melt at a given speed.

\section{Conclusion}

Thus, as a result of studies it was shown that the method of obtaining semi-finished products with combined rolling-extrusion of aluminum alloys having different ductility, including recycled 

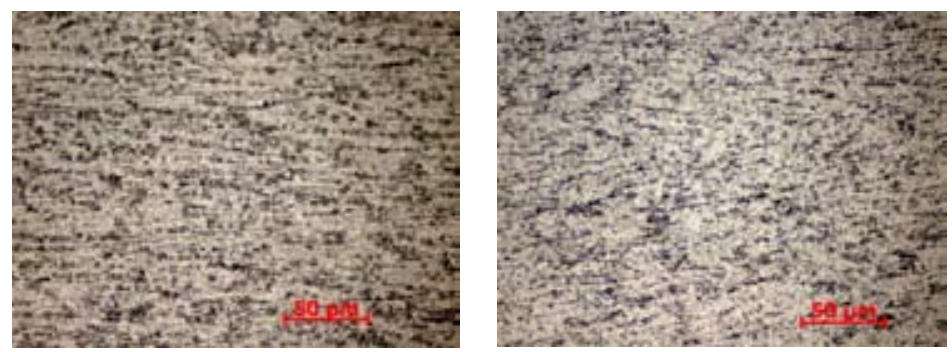

$\mathrm{a}-480{ }^{\circ} \mathrm{C}$

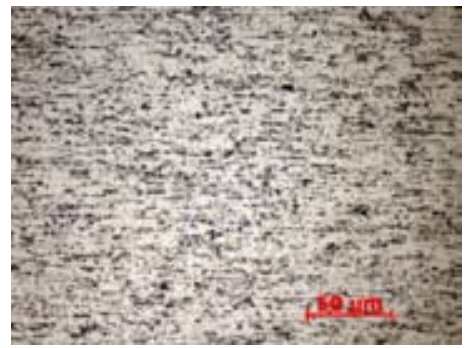

$\mathrm{C}-480{ }^{\circ} \mathrm{C}$ $b-525^{\circ} \mathrm{C}$

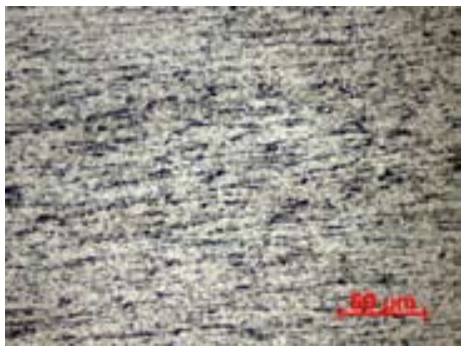

$d-525{ }^{\circ} \mathrm{C}$

Fig. 4. Microstructure of rods $(\times 500)$ from alloy AV93 obtained by method CRE at a strain rate $\xi=0,74 \mathrm{~s}^{-1}$ : $\mathrm{a}, \mathrm{b}$ - diameter $9 \mathrm{~mm}$; c, $\mathrm{d}$-diameter $7 \mathrm{~mm}$

aluminum AV93. It was found that for the production of billets of such alloys with a uniform structure need special kinds of castings, such as electromagnetic casting mold. Getting cheap extruded semifinished of secondary aluminum alloys will increase the efficiency of deoxidation of steel. The results of research and experience in the use of the combined process of rolling-extrusion to handle the secondary alloy AV93 can be extended to other brands of secondary hard-deformable and low-ductile aluminum alloys.

\section{References}

[1] Sidelnikov S.B., Dovzhenko N.N. Zagirov N.N. Combined methods of treatments of non-ferrous metals and alloys: a monograph. M.: MAKS Press, 2005. P. 344.

[2] Sidelnikov S.B., Grishechkin A.I., Dovzhenko N.N. // The technology of lightweight alloys. 2002. № 5-6. P. 41-44.

[3] Sidelnikov S.B., Galiev R.I., Dovzhenko N.N.. Belyaev S.V. // Collection of materials AllRussian scientific-practical conference «Technological quality assurance of machines and devices». Privolzhsky house of knowledge. Penza, 2004. P. 12-15.

[4] Kolpashnikov A.I., Efremov A.V. Granulated materials. M.: Metallurgy, 1977. 240 p.

[5] Sidelnikov S.B., Dovzhenko N.N., Timofeev V.N. Installation for continuous casting rolling and extruding. Patent RF № 67492. / Publ. 27.10.2007. Bul. № 30. 